\title{
Participant evaluation of simulation training using crew resource management in a hospital setting in Hong Kong
}

\author{
Christina KW Chan *, Eric HK So, George WY Ng, Teresa WL Ma, Karen KL Chan, LY Ho
}

\section{A B S T R A C T}

Introduction: A simulation team-based crew resource management training programme was developed to provide a unique multidisciplinary learning experience for health care professionals in a regional hospital in Hong Kong. In this study, we evaluated how health care professionals perceive the programme.

Methods: A cross-sectional questionnaire survey was conducted in the Multidisciplinary Simulation and Skills Centre at Queen Elizabeth Hospital in Hong Kong. A total of 55 individuals in the departments of Obstetrics and Gynaecology, Anaesthesiology and Operating Theatre Services, Intensive Care Unit, and Accident and Emergency participated in the study between June 2013 and December 2013. The course content was specially designed according to the needs of the clinical departments and comprised a lecture followed by scenarios and debriefing sessions. Principles of crew resource management were introduced and taught throughout the course by trained instructors. Upon completion of each course, the participants were surveyed using a 5-point Likert scale and open-ended questions.

Results: The participant's responses to the survey were related to course organisation and satisfaction, realism, debriefing, and relevance to practice. high, with mean Likert scale scores of 4.1 to 4.3. The key learning points were identified as closedloop communication skills, assertiveness, decision making, and situational awareness.

Conclusions: The use of a crew resource management simulation-based training programme is a valuable teaching tool for frontline health care staff. Concepts of crew resource management were relevant to clinical practice. It is a highly rated training programme and our results support its broader application in Hong Kong.

\section{Hong Kong Med J 2016;22:131-7}

\section{DOI: $10.12809 / \mathrm{hkmj} 154595$}

${ }^{1}$ CKW Chan *, BSc, MPH

${ }^{2}$ EHK So, FHKCA, FHKAM (Anaesthesiology)

${ }^{3}$ GWY Ng, FHKCP, FHKAM (Medicine)

${ }^{4}$ TWL Ma, FRCOG, FHKAM (Obstetrics and Gynaecology)

${ }^{5}$ KKL Chan, FHKCEM, FHKAM (Emergency Medicine)

${ }^{1}$ LY Ho, FRCS (Urology), FHKAM (Surgery)

\section{Multidisciplinary Simulation and Skills Centre \\ Anaesthesiology and Operating Theatre Services \\ ${ }^{3}$ Intensive Care Unit \\ ${ }^{4}$ Department of Obstetrics and Gynaecology \\ ${ }^{5}$ Accident and Emergency Department \\ Queen Elizabeth Hospital, Jordan, Hong Kong}

The overall rating of the training programme was * Corresponding author: mdssc_research@ha.org.hk

New knowledge added by this study

- Our data support the use of crew resource management (CRM) in a simulation-based training programme as an effective means for teaching health care professionals in a public hospital setting in Hong Kong. Programmes may need to be customised for each specialty, however. Our results showed that this type of training is highly rated and accepted by frontline health care professionals.

Implications for clinical practice or policy

A key area for future improvement in health care providers is to teach and practise CRM. CRM has been recognised as an effective educational tool in health care organisations. Its broader application in Hong Kong should be encouraged.

\section{Introduction}

Simulation-based training is increasingly recognised as a useful educational tool in health care organisations. ${ }^{1}$ Within an acute care setting, these tools are used for various training purposes, for example, teaching technical ${ }^{2}$ and non-technical ${ }^{3,4}$ skills and rehearsing rare events..$^{5}$ Simulation is a technique "to replace or amplify real [patient] experiences with guided experiences that evoke or replicate substantial aspects of the real world in a fully interactive manner". ${ }^{6}$ With the application of adult learning theory, ${ }^{7}$ simulation-based training is usually designed to resemble the reality and allows trainees to acquire knowledge, skills, and 


\section{香港醫護人員對於使用「機員資源管理」作模擬 訓練的評估}

陳嘉慧、蘇恆光、吳榮耀、馬慧玲、陳建凌、何立言

引言：香港一所分區醫院推出了一個「機員資源管理」（CRM）的模 擬訓練課程, 讓醫護人員有獨特的跨部門學習機會。這研究評估參與 者對CRM的看法。

方法：我們在香港伊利沙伯醫院綜合模擬及技能培訓中心進行一項橫 斷面問卷研究。2013年6月至 12 月期間共55位於婦產科、麻醉科、深 切治療部和急症室的醫護人員分別參與了「優化醫療團隊管理課程」 。該課程的設計是配合不同部門於培訓需求分析所得出的個別需要, 內容包括課堂講解和在模擬醫院場景下進行模擬訓練及事後講評, 於 事後講評中由導師帶出CRM的原理。課程結束後, 每位參與者均完成 5 點李克特量表和開放式問卷調查以作課程評估。

結果：課程的評估內容包括參加者對於課程的組織和滿意度、真實 感、事後講評以及臨床實踐。參加者對課程給予頗高評分, 在 5 點李 克特量表中取得平均 4.1 至 4.3 分。參與者認為此課程的學習重點包括 完成溝通迴圈、肯言、決策及狀況認知。

結論：對前線醫療人員而言, 優化醫療團隊管理模擬培訓計劃是一個 寶貴的教學工具, 它的概念能應用於醫療上的臨床實踐。這次研究計 劃中, 發現前線醫療人員對類似的培訓有頗高的評價, 證明在香港醫 療機構廣泛推廣同類型的培訓計劃需求殷切。 competence in a safe and controlled environment. ${ }^{8,9}$ Studies have shown that teamwork plays an important role in the prevention of adverse events and errors. ${ }^{10,11}$ Simulation-based training programmes that focus on crew resource management (CRM) criteria have been found to effectively improve teamwork skills. Such criteria emphasise teaching of non-technical skills, such as communication, leadership, assertiveness, and situational awareness, thereby improving patient safety. ${ }^{12,13}$

Crew resource management is a risk-reduction programme of the Hospital Authority (HA) in Hong Kong and has run since 2009. Between 2009 and 2012, Pamela Youde Nethersole Eastern Hospital piloted the classroom-based CRM programme to approximately 2000 staff in the hospital. ${ }^{14}$ The programme received positive feedback from staff and the impact on patient safety was evident in the programme evaluation. Thus, the HA decided that a second-phase roll-out of CRM was necessary because there was a need for team-based training. Queen Elizabeth Hospital (QEH) and Tuen Mun Hospital were the two public hospitals selected to implement the second pilot programme of the CRM focusing on specialty-based simulation training.

The Multidisciplinary Simulation and Skills Centre (MDSSC) at QEH has developed a simulation team-based CRM training programme. This new training programme provides a unique multidisciplinary learning experience for health care professionals at QEH. The MDSSC used this opportunity to evaluate how health care professionals perceive the programme.

\section{Methods}

\section{The train-the-trainer workshop}

In order to roll out the second phase of the CRM programme to QEH, HA engaged Safer Healthcare ${ }^{15}$ to advise on the development and delivery of CRM training courses. A 3-day on-site CRM train-thetrainer workshop was held at MDSSC between March and April 2013. The workshop was intended for doctors and nurses working at QEH who were interested in teaching medical education and would like to become a CRM-certified trainer. All workshops were taught by experienced instructors from Safer Healthcare. ${ }^{15}$ The content of the workshops included reviewing the use of CRM in health care, delivering the CRM principles, enhancing presentation skills, and handling difficulties and challenges in team debriefing. All trainees had the unique opportunity to develop scenarios using CRM principles. A total of 40 doctors and nurses were trained and certified to teach CRM courses.

\section{Curriculum design}

In order to determine the components of CRM training most appropriate for frontline health care staff, a survey was conducted of all frontline health care staff in four selected high-risk areas where teamwork is essential for satisfactory patient outcome: Obstetrics and Gynaecology (O\&G), Anaesthesiology and Operating Theatre Services (Anaes \& OTS), Intensive Care Unit (ICU), and Accident and Emergency (A\&E). The survey was designed to assess staff perception of teamwork and patient safety, obstacles, and challenges encountered in the workplace, and areas where training was wanted. Some of the questions were based on the most common reasons why medical errors occur among the four specialties as well as from the literature. ${ }^{16-18}$ The survey consisted of seven multiplechoice and rating-scale questions about teamwork, patient safety, the obstacles and challenges in practice, and training needs (Table 1 ).

The CRM curriculum for the four specialties was first proposed by the course coordinators who were the specialist consultants and associate consultants from respective departments at QEH. The course coordinators first identified their staffing needs based on the results of the survey. They developed a specialty-based training programme that addressed their frontline staff learning needs and was related to the type of sentinel and serious untoward events reported. This would enable participants to learn non-technical CRM skills and apply them in their 
TABLE I. Training needs survey

\begin{tabular}{|c|c|}
\hline 1.* & How would you rate the current overall level of teamwork and collaboration in your area/department? \\
\hline 2.* & How would you rate the current level of communication between physicians and nurses in your area/department? \\
\hline 3.† & What are the factors that prevent you from having excellent communication and teamwork in your area? \\
\hline 4.* & How would you rate the patient safety in your area/unit? \\
\hline $5 . \dagger$ & What are some of the obstacles and challenges that currently exist in your area(s) that prevent you from focusing on patient safety? \\
\hline $6 . \dagger$ & Could you choose one clinical scenario in daily practice that you would like to receive training on? \\
\hline 7.† & What do you think should be the number one priority in patient journey at your area/unit? \\
\hline
\end{tabular}

* Rating scale of $\mathrm{I}-\mathrm{I} 0$, with 10 being very satisfied and I being very unsatisfied

† Multiple-choice questions

workplace when making clinical judgements and performing procedures. The specialty-based training programme comprised three components: a lecture, games, and scenarios. Each scenario was customised for each specialty in order to fulfil its learning objectives, specific educational outcomes, and needs of the department in order to enhance participants' learning experience. All scenario practice sessions included CRM principles as defined in Table 2 and were chosen according to the needs at $\mathrm{QEH}$.

After the programmes had been endorsed by the department head, the directors of MDSSC reviewed and evaluated the programme. Feedback and recommendations were given to course coordinators so they could improve the quality of the training, and ensure CRM components were included and that the course supported the MDSSC's mission statement. The course coordinators made changes according to the reviewers' comments. A confirmation of the booking date was given to the course coordinators once the programme had been endorsed by the reviewers. The evaluation of a programme required approximately 2 weeks to complete (Fig 1).

\section{The training programme}

The CRM training programme took place between June and December 2013. The training began with a lecture introducing the background of CRM. A game was played afterwards and served as an icebreaker' and illustrated the importance of teamwork, leadership, and decision making.

Next, simulation training was conducted with two scenarios followed by a debriefing session. Each scenario was performed by a group of four to five health care frontline staff. Members of each group participated in the debriefing after each simulation scenario. The role of the trainer was to lead a discussion about team strengths and areas for improvement. This allowed participants to reflect on their experience related to CRM skills and clinical knowledge in the scenarios. Participants may also have learnt new concepts and techniques that could be applied in daily practice. All training was given at MDSSC and conducted by experienced certified CRM trainers.

TABLE 2. Principles and skills of crew resource management

\begin{tabular}{ll}
\hline CRM principle & Skill \\
\hline Leadership & Conflict management \\
& Decision making \\
\hline Communication & SBAR \\
& Closed-loop communication \\
\hline Assertiveness & Speaking up \\
\hline Situational awareness & Recognising events around us \\
\hline
\end{tabular}

Abbreviations: $C R M=$ crew resource management; $S B A R=$ Situation-Background-Assessment-Recommendation

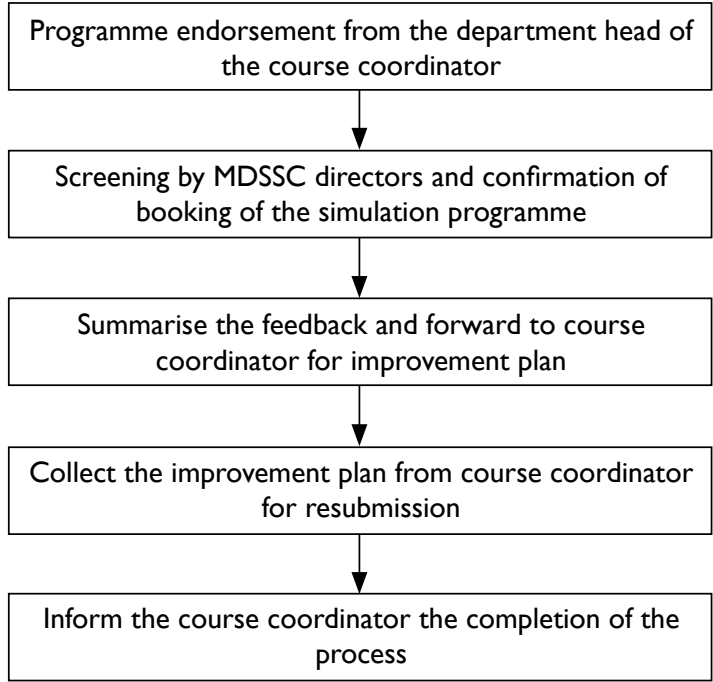

FIG I. The MDSSC Curriculum Committee application screening process

Abbreviation: MDSSC = Multidisciplinary Simulation and Skills Centre 


\section{Sample}

Participants were recruited from four high-risk departments at QEH through nominations based on their availability. The study sample included doctors and nurses working in the frontline area of these four departments: O\&G, Anaes \& OTS, ICU, and A\&E. Each participant was assigned a specific role during each scenario. The role could be changed for different simulation scenarios. All participants received the same educational content and simulation opportunities.

\section{Data collection}

Participants evaluated the CRM simulation training by anonymous completion of a questionnaire that comprised six open-ended questions and 14 questions that were answered on a 5-point Likert scale $(1=$ strongly disagree, $2=$ disagree, $3=$ neutral, $4=$ agree, $5=$ strongly agree). Open-ended questions focused on the areas of learning needs, the specific areas where CRM can be implemented, the learning points that were applicable to practice, and recommendation of the programme to other colleagues. The first section aimed to obtain information about the training programme. The open-ended questions were asked to elicit qualitative responses related to learning and demographic information. The evaluation was paper-based and completed by participants at the end of the training programme.

\section{Statistical analysis}

The data were tabulated using Microsoft Excel and analysed using the STATA 13. Demographic information of participants was reported as frequency (\%) and participant scores were reported as mean \pm standard deviation.

\section{Results}

\section{Training needs analysis}

A total of 380 frontline health care staff were invited to participate in the training needs survey that was completed by $319(84 \%)$. The mean satisfaction rating on a scale of 1 to 10 for overall level of teamwork and collaboration, the current level of communication between physicians and nurses, and patient safety on their unit was 6.5, 6.2, and 7.1, respectively. Factors that prevented frontline health care staff from achieving excellent communication and teamwork included different types of personality among colleagues $(n=92,29 \%)$, too many things to attend to at the same time $(\mathrm{n}=85,27 \%)$, a culture that prevented an individual from speaking out $(\mathrm{n}=73,23 \%)$, lack of a standard communication format $(\mathrm{n}=39,12 \%)$, and fear of being wrong $(n=30,9 \%)$. The obstacles and challenges that prevented them from focusing on patient safety included inadequate manpower $(\mathrm{n}=85$, $27 \%)$, heavy workload $(n=80,25 \%)$, time pressure $(n=77,24 \%)$, poor team communication $(n=51,16 \%)$, and insufficient equipment $(n=26,8 \%)$. The top five areas in which staff would like to receive training were handling a difficult patient $(\mathrm{n}=118,37 \%)$, handover of critical cases $(n=85,27 \%)$, briefing and debriefing $(n=48,15 \%)$, collapse in the operating theatre/ward $(n=42,13 \%)$, and difficult airway $(n=26,8 \%)$. Good leadership and decision making was considered by $86(27 \%)$ of staff to be the top priority in patient care, followed by good clinical skill and knowledge $(\mathrm{n}=78$, $24 \%)$, good team communication $(\mathrm{n}=69,22 \%)$, more manpower $(\mathrm{n}=57,18 \%)$, and better clinical environment $(n=29,9 \%)$ [Fig 2].

\section{The training programme}

The number of frontline health care staff eligible for the study in the O\&G, Anaes \& OTS, ICU, and A\&E departments was $135,106,70$, and 69 , respectively. Among them, 55 (of whom 40 were female and 36 were nurses) were nominated to participate in the study and completed the simulation training programme. They included 23 participants from O\&G, 10 from Anaes \& OTS, 12 from ICU, and 10 from A\&E. The characteristics of these participants are summarised in Table 3.

\section{Likert-scale questions}

Participant responses to the Likert-scale questions were very positive, with mean scores of 4.1 to 4.3 . Almost all participants responded positively with either 'strongly agree' or 'agree' to questions about overall satisfaction with the training programme, the applicability of the programme to area of practice, and high standard and expertise of the trainers. The question that received the lowest mean rating was related to the ability of scenarios to facilitate decision making. Nonetheless this question was still considered 'agree' on a scale of 1 (strongly disagree) to 5 (strongly agree). None of the questions were rated 'disagree' or 'strongly disagree'. Participant ratings for all 14 questions are summarised in Table 4.

\section{Open-ended questions}

For the open-ended questions, $85 \%(47 / 55)$ of participants stated that they would recommend the programme to other colleagues and $15 \%$ did not respond to this question. Of the 55 participants, 11 commented on learning more about closed-loop communication, situational awareness, assertiveness, conflict resolution, decision making, and leadership. Six participants commented positively on the course itself. Specifically, comments were related to CRM elements: "the CRM training is very useful to our clinical work and even to our daily life" and "the 

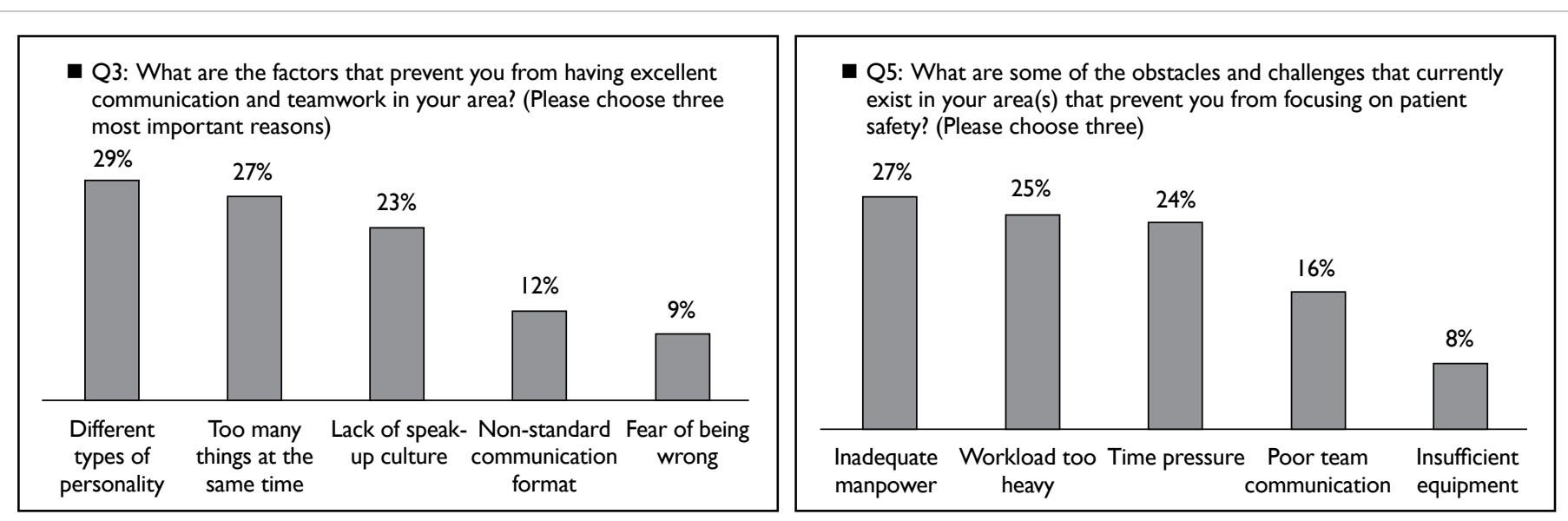

Q6: Could you choose one clinical scenario in daily practice that you would like to receive training on?

$37 \%$

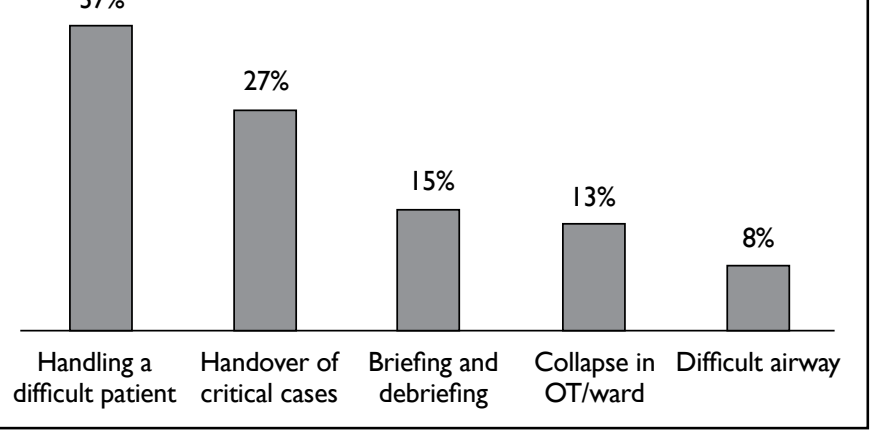

Q7: What do you think should be the number one priority in patient journey at your area/unit? (Please choose three)

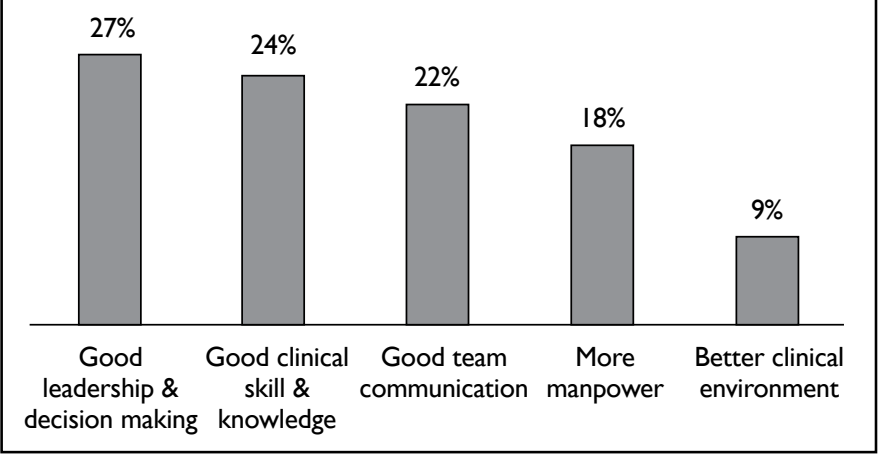

FIG 2. Training needs analysis for frontline health care professionals (Questions 3, 5, 6, and 7)

Abbreviation: OT = operating theatre

TABLE 3. Demographic information of participants

\begin{tabular}{lcc}
\hline Demographics & \multicolumn{2}{c}{ No. (\%) } \\
\cline { 2 - 3 } & Staff participated $(\mathbf{n}=\mathbf{5 5})$ & Eligible staff $(\mathbf{n}=\mathbf{3 8 0})$ \\
\hline Sex & & - \\
\hline Female & $40(73)$ & - \\
\hline Male & $15(27)$ & $70(18)$ \\
Job discipline & & $310(82)$ \\
\hline Doctors & $19(35)$ & \\
Nurses & $36(65)$ & $135(36)$ \\
Department & & $106(28)$ \\
\hline Obstetrics and Gynaecology & $23(42)$ & $70(18)$ \\
Anaesthesiology and Operating Theatre Services & $10(18)$ & $69(18)$ \\
\hline Intensive Care Unit & $12(22)$ & \\
\hline Accident and Emergency & $10(18)$ & \\
\hline
\end{tabular}

CRM videos are funny and useful". The remaining assertiveness, decision making, and situational comments were "good", "a pleasant experience", and awareness.

"the programme was useful".

When asked to list the learning points applic- Discussion

able to work, participants most commonly responded Training in non-technical skills is essential for health to the CRM elements, such as communication skills, care professionals to enhance patient safety and 
TABLE 4. Participant responses regarding the crew resource management simulation training programme $(n=55)$

\begin{tabular}{llc}
\hline Question from course evaluation & $\begin{array}{c}\text { Mean } \pm \text { standard deviation (\% of } \\
\text { responses with rating of } \mathbf{4} \text { or 5) }\end{array}$ \\
\hline 1. & The programme has achieved its stated goals. & $4.2 \pm 0.5(94.5)$ \\
\hline 2. & This programme met training needs. & $4.1 \pm 0.5(94.6)$ \\
\hline 3. & The programme that I learned can be applied to my practice. & $4.3 \pm 0.5(98.1)$ \\
\hline 4. & The programme is organised. & $4.2 \pm 0.5(96.4)$ \\
\hline 5. & Length of the course is appropriate. & $4.1 \pm 0.5(90.9)$ \\
\hline 6. & Trainers are of high standard and expertise. & $4.2 \pm 0.5(98.2)$ \\
7. & The course materials are well prepared. & $4.2 \pm 0.5(94.5)$ \\
\hline 8. & Scenarios are realistic. & $4.2 \pm 0.6(90.9)$ \\
\hline 9. & Scenarios are able to facilitate decision making. & $4.1 \pm 0.7(83.6)$ \\
\hline 10. & Debriefing session is useful. & $4.4 \pm 0.6(96.4)$ \\
11. & Simulation is more powerful than lecture-based training for this programme. & $4.4 \pm 0.6(96.4)$ \\
12. & I am overall satisfied with this training programme. & $4.3 \pm 0.5(98.2)$ \\
\hline 13. & Trainer is effective in facilitating my learning. & $4.3 \pm 0.6(96.4)$ \\
\hline 14. & Trainer helped me understand my performance. & $4.3 \pm 0.6(90.9)$ \\
\hline
\end{tabular}

teamwork. ${ }^{19}$ Hospital patients are normally treated by a team having various disciplines; therefore, team training is important to prevent human error.

High realism simulation is becoming widely used in health care education. ${ }^{20-23}$ It creates a realistic risk-free environment for learners to practise and improve confidence in life-saving skills.

In our study, frontline health care staff surveyed at MDSSC reacted positively to their initial experience with CRM training, suggesting that this is a favourable means by which to provide simulationbased training. Almost all participants (91\%-98\%) rated their level of agreement as high or very high for overall course organisation, course content, trainer performance, programme satisfaction, training needs, and the usefulness of debriefing session. These findings indicate that simulation-based CRM training was well accepted by frontline health care staff and they would likely benefit from simulationbased scenarios, and is consistent with a previous study. ${ }^{24}$

A number of participants stated that they would recommend the programme to other colleagues. Participants made very positive comments about the CRM simulation-based training programme and perceived CRM as an important means to improve their teamwork skills. Although CRM can be taught in a didactic approach, we believe that a simulation approach has the advantage of motivating participants to learn about teamwork skills and to alter their behaviour, so reducing the risk of adverse events. This type of training will help health care professionals incorporate the CRM principles into their daily practice.
To our knowledge, this is the first study to specifically address the use of CRM in a tailor-made specialty-based simulation training programme in multiple clinical departments in a public hospital in Hong Kong. Prior to this study, we distributed a training needs survey to all frontline staff among the four specialties that asked about their perception of teamwork and learning needs. The results from this survey provided a clear idea about the design of scenarios. The topics and content were also appropriate and could contribute to the development of teamwork in a health care organisation. In terms of teaching quality, all instructors were certified and had completed the same CRM train-the-trainer programme, thus teaching methods were consistent.

There are several limitations to this study. First, it was undertaken in a single hospital and analysed a simulation-based CRM training programme specifically designed for each specialty. Its generalisation to other CRM simulation-based programmes in other multidisciplinary settings may be limited. Second, the sample size was small. Nonetheless this pilot study was designed to determine staff perception of learning CRM rather than to demonstrate efficacy. Furthermore, the participants were recruited through nomination. It is unclear whether those who were nominated to participate may differ to those who were not nominated (in terms of their characteristics). The results may reflect a possible selection bias as participants may be more inclined to participate and learn from such a training programme. Other limitations include the training needs survey that was a self-report, not an objective assessment, and 
was limited to the categories included in the survey. The optional "other" response was rarely used by the participants, however. Finally, although the survey demonstrated a high level of acceptance of and satisfaction with simulation-based CRM training, this does not necessarily translate into improved frontline health care performance. Further research in this area is needed.

\section{Conclusions}

We have developed and rolled out a specialtybased simulation CRM training programme in a public hospital setting in Hong Kong. Our findings demonstrate that CRM appeared to be highly valued by participants and was applicable to their daily practice. It also demonstrated that training needs analysis may be useful to develop the content of a simulation CRM training programme. The culture of patient safety needs time to change however, and this programme is just the first step in developing a safety culture in health care organisations.

\section{Acknowledgements}

The MDSSC team would like to express its gratitude to HA Head Office for their support and contribution in this study. Without their support, the study could not have been completed.

\section{References}

1. Cook DA, Hatala R, Brydges R, et al. Technology-enhanced simulation for health professions education: a systematic review and meta-analysis. JAMA 2011;306:978-88.

2. Boet S, Bould MD, Schaeffer R, et al. Learning fibreoptic intubation with a virtual computer program transfers to 'hands on' improvement. Eur J Anaesthesiol 2010;27:315.

3. Yee B, Naik VN, Joo HS, et al. Nontechnical skills in anesthesia crisis management with repeated exposure to simulation-based education. Anesthesiology 2005;103:2418.

4. Kneebone R, Nestel D, Wetzel C, et al. The human face of simulation: patient-focused simulation training. Acad Med 2006;81:919-24.

5. Decarlo D, Collingridge DS, Grant C, Ventre KM. Factors influencing nurses' attitudes toward simulation-based education. Simul Healthc 2008;3:90-6.

6. Gaba DM. The future vision of simulation in healthcare. Simul Healthc 2007;2:126-35.

7. Speck M. Best practice in professional development for sustained educational change. ERS Spectr 1996;14:33-41.

8. Kneebone RL, Scott W, Darzi A, Horrocks M. Simulation and clinical practice: strengthening the relationship. Med Educ 2004;38:1095-102.

9. Ziv A, Wolpe PR, Small SD, Glick S. Simulation-based medical education: an ethical imperative. Simul Healthc 2006;1:252-6.

10. Manser T. Teamwork and patient safety in dynamic domains of healthcare: a review of the literature. Acta Anaesthesiol Scand 2009;53:143-51.

11. Künzle B, Kolbe M, Grote G. Ensuring patient safety through effective leadership behaviour: a literature review. Saf Sci 2010;48:1-17.

12. Kosnik LK. The new paradigm of crew resource management: just what is needed to re-engage the stalled collaborative movement? Jt Comm J Qual Improv 2002;28:235-41.

13. Risser DT, Rice MM, Salisbury ML, Simon R, Jay GD, Berns SD. The potential for improved teamwork to reduce medical errors in the emergency department. The MedTeams Research Consortium. Ann Emerg Med 1999;34:373-83.

14. Hospital Authority Quality and Risk Management. Annual Report (2012-2013). Hong Kong: Hospital Authority; 2013: 10-1.

15. Marshall DA, Manus DA. A team training program using human factors to enhance patient safety. AORN J 2007;86:994-1011.

16. O'Daniel M, Rosenstein AH. Professional communication and team collaboration. In: Hughes RG, editor. Patient safety and quality: an evidence-based handbook for nurses. Rockville (MD): Agency for Healthcare Research and Quality (US); 2008.

17. Leonard M, Graham S, Bonacum D. The human factor: the critical importance of effective teamwork and communication in providing safe care. Qual Saf Health Care 2004;13 Suppl 1:i85-90.

18. Manojlovich M, Antonakos CL, Ronis DL. Intensive care units, communication between nurses and physicians, and patients' outcomes. Am J Crit Care 2009;18:21-30.

19. Gordon M, Darbyshire D, Baker P. Non-technical skills training to enhance patient safety: a systematic review. Med Educ 2012;46:1042-54.

20. Bruppacher HR, Alam SK, LeBlanc VR, et al. Simulationbased training improves physicians' performance in patient care in high-stakes clinical setting of cardiac surgery. Anesthesiology 2010;112:985-92.

21. Burkhart HM, Riley JB, Hendrickson SE, et al. The successful application of simulation-based training in thoracic surgery residency. J Thorac Cardiovasc Surg 2010;139:707-12.

22. Sexton JB, Makary MA, Tersigni AR, et al. Teamwork in the operating room: frontline perspectives among hospitals and operating room personnel. Anesthesiology 2006;105:877-84.

23. Seymour NE, Gallagher AG, Roman SA, et al. Virtual reality training improves operating room performance: results of a randomized, double-blinded study. Ann Surg 2002;236:458-63; discussion 63-4.

24. Blum RH, Raemer DB, Carroll JS, Sunder N, Felstein DM, Cooper JB. Crisis resource management training for an anaesthesia faculty: a new approach to continuing education. Med Educ 2004;38:45-55. 